\title{
Investigation of Occupational Noise Exposure in a Ship Recycling Yard
}

Rafet Emek Kurt ${ }^{\mathrm{a}}{ }$, Stuart Alexander McKenna ${ }^{\mathrm{a}}$, Sefer Anil Gunbeyaz ${ }^{\mathrm{a}}$, Osman Turan ${ }^{\mathrm{a}}$

${ }^{a}$ University of Strathclyde, Department of Naval Architecture, Ocean and Marine Engineering, 100 Montrose Street, G40LZ, Glasgow, U.K.

\section{Highlights}

This quantitative study investigated occupational noise exposure in a ship recycling yard and found that:

- Ship recycling workers are at risk from occupational noise induced hearing loss

- Torch cutters are exposed to noise levels above the exposure limit values of $87 \mathrm{~dB}$ (A) and $140 \mathrm{~dB}(\mathrm{C})$

- There is extremely poor occupational health compliance and protection in relation to noise within the ship recycling industry

- Further research is required to determine the true extent of occupational noise induced hearing loss amongst ship recycling workers

\begin{abstract}
The ship recycling industry is often criticised for unacceptable occupational health and safety practices. In order to support the development of technical solutions and new regulatory norms, there is an urgent need for quantitative data explaining the impacts of ship recycling practices on health and safety. Therefore, this study investigated hazardous noise exposure in ship recycling yards by identifying the sources of noise, quantifying their potential impacts on workers and making recommendations for improvement. A noise exposure investigation in an operational ship recycling yard was conducted, which comprised a general noise survey, a personal noise exposure measurement for workers and comparison of the results with the exposure limits and action values defined by the European Union's Physical Agents (Noise) Directive (EC 2003b). The results of this study show that ship recycling workers are at risk of experiencing occupational noise induced hearing loss as a result of being exposed to hazardous noise levels for prolonged periods of time. This study explains that those working with torch cutting equipment, in particular, are most at risk. The study also shows that there is currently a lack of appropriate hearing protection being used in ship recycling yards.
\end{abstract}

Keywords: Ship Recycling; Ship Dismantling; Noise Exposure; Hearing Loss; Occupational Noise

\footnotetext{
${ }^{1}$ Corresponding author: Tel: +44 (0)141 5484697 | Email:rafet.kurt@strath.ac.uk
} 


\section{Introduction}

Ship recycling is a heavy industry that is primarily performed in developing countries where a demand for scrap metal and second hand equipment is prevalent. In the past, countries such as Taiwan and South Korea were the dominant nations within the industry; at present, India, Pakistan, Bangladesh, China and Turkey possess $98 \%$ of the total market share (Mikelis, 2013).

Typical ship recycling operations in the countries mentioned above are labour intensive, and workers have been observed being exposed to a variety of occupational hazards (ILO, 2004; OSHA, 2010) which have unfortunately led to accidents, illness and even death (Wu et al., 2015). Legislative efforts, in the form of the International Maritime Organisation's (IMO) Hong Kong convention (IMO, 2009) (International Convention for the Safe and Environmentally Sound Recycling of Ships) and the European Commission's Ship Recycling Regulation (EC, 2013), are in the process of establishing a framework of improvement. However, a lack of quantified data underpinning the true extent of the unique occupational health and safety challenges within a ship recycling context are hampering efforts.

Through an initial literature review of ship recycling related research, one specific occupational health issue which was identified as requiring attention was the risk of occupational noise induced hearing loss (ONIHL). Exposure to noise can be considered as one of the most common occupational hazard in the world (Bogardus Jr et al., 2003; Ferrite and Santana, 2005; Koh and Jeyaratnam, 1998; Yueh et al., 2003). According to Nelson et al. (2005) occupational noise exposure is considered as a cause for $16 \%$ of disabling hearing loss in adults. In a similar study Tak and Calvert (2008) analysed more than 130,000 responses given to National Health Interview Survey in U.S. and concluded that $11.4 \%$ of the population experience hearing difficulty, $24 \%$ of which is attributable to occupational noise. In the E.U., one study has suggested that $28 \%$ of the workers experience high noise levels at work at least one fourth of the time (EASHW, 2000). Many workers engaged in heavy industry, factories, forge hammering, coal and ore mining, construction, cement plants, the gas processing industry and mechanical engineering, as well as mill and stationary machine device operators and workers at oil refineries have been identified as being at risk of ONIHL (Azizi, 2010). Furthermore, besides its direct health effects, there are many studies (Cohen, 1974; Melamed et al., 2004) which show that noise exposure coupled with hearing loss interfere with safety, as $12.2 \%$ of accidents can be related to noise exposure (Picard et al., 2008). Ship recycling is a heavy industry and it is suspected that ship recycling workers are being exposed to intermittent or continuous hazardous noise levels $(>85 \mathrm{~dB}(\mathrm{~A}))$ in their working environments and are subsequently at risk from ONIHL.

At the beginning of this study, it became apparent that no previous studies of noise exposure or ONIHL had been conducted specifically for ship recycling operations. Therefore, studies conducted in other sectors as well as shipbuilding and ship repair yards were used as an initial reference point for activities where the use of heavy plant machinery, moving steel plates, and cutting and welding using torches were judged to be of a similar nature to the core ship recycling activities.

Chute (2012) conducted personal noise dosimetry and noise level surveys during selected tasks in four shipyards. The findings showed that out of 30 full shift dosimetry results $43 \%$ exceeded 
the Occupational Safety and Health Administration's (OSHA) Permissible Exposure Limit (PEL) Criteria of 90dB(A), 73\% exceeded the OSHA's Hearing Conservation trigger level of $85 \mathrm{~dB}(\mathrm{~A})$, and $90 \%$ exceeded the American Conference of Governmental Industrial Hygienists (ACGIH) Threshold Limit Values (TLV) criteria of $85 \mathrm{~dB}(\mathrm{~A})$.

A study by Toppila et al. (2005) reported that the average noise level observed in a shipyard ranged between 93-95dB(A). Similarly, research conducted by Kihlman et al. (1976) showed that the average noise level experienced by a welder in a shipyard was $96 \mathrm{~dB}(\mathrm{~A})$, while a plater was exposed to $100 \mathrm{~dB}(\mathrm{~A})$ noise level on average. Furthermore, analysis revealed that $41 \%$ of the workers had already experienced a slight loss of hearing and $15 \%$ had experienced a serious loss of hearing.

Nilsson et al. (1977) conducted a study of 1492 workers in a shipyard which showed that $58.1 \%$ of the workers had some level of hearing problem, with $20.4 \%$ of the workers being diagnosed as having severe ONIHL. In addition, hearing tests conducted by Ross (1978) on 926 British welders with heavy engineering and shipyard experience showed that in 40-49 year old welders, $70 \%$ had a hearing loss at $4 \mathrm{kHz}$ of over $40 \mathrm{~dB}$ in the left ear, $60 \%$ had the same hearing loss in the right ear, and over $20 \%$ had a hearing loss greater than $60 \mathrm{~dB}$.

Finally, more recent research confirms that ONIHL continues to be a problem in shipbuilding and repair related environments. Alexopoulos and Tsouvaltzidou (2015) reported that 27.1\% of the employees were hearing handicapped in a study conducted in a shipyard in Greece. A similar study revealed that $6 \%$ of the employees of a shipbuilding yard in India had ONIHL (Bhumika et al., 2013).

In summary, the review of literature from analogous industries suggested that the issue of ONIHL was going to be applicable to ship recycling workers and that further investigation was required. Due to commercial and political restrictions, it was not possible to conduct hearing tests to identify the actual impacts on a typical ship recycling workforce's hearing. However, we were able to investigate potential noise exposure generated during realistic ship recycling operations through a dedicated measurement campaign.

\section{Material and methods}

In order to implement a measurement campaign, access to an operational ship recycling yard was negotiated on the terms that the details of the yard would remain confidential. The yard chosen and its working practices were representative of a typical ship recycling yard. Additionally, the country in which the measurements were made has officially adopted EU's Physical Agents (Noise) Directive (EC 2003b).

This study was conducted in a manner as close as practicable to the measurement method defined by ISO 9612-2009 Acoustics Determination of Occupational Noise Exposure: Engineering method (ISO, 2009). Figure 1 presents an overview of the experimental procedure followed within this investigation. 


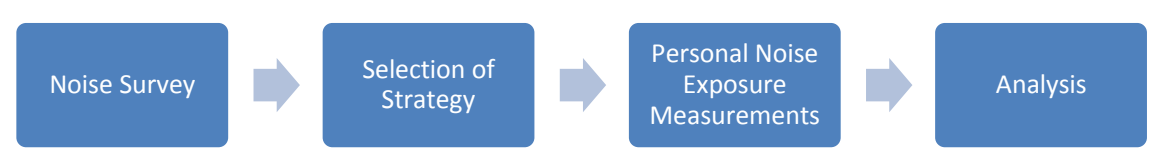

Figure 1: Experiment Methodology Overview

Initially, an overall noise survey of the yard was conducted to identify zones in the yard where occupational noise problems may be present. This survey was carried out using a sound level meter (Bruel Kjaer Hand Held Analyser Type 2250). The sound level meter used was in full compliance with IEC (2003b) 61672:2003 Type 2, certified as being recently calibrated in accordance with ISO (2005) EN ISO/IEC 17025 and checked using an acoustical calibrator compliant with IEC (2003a) 60942:2003 before and after the measurements. The device had an acoustic measuring range of $50 \mathrm{~dB}(\mathrm{~A})$ to $120 \mathrm{~dB}(\mathrm{~A})$ Root Mean Square (RMS) with an estimated accuracy of $\pm 2 \mathrm{~dB}(\mathrm{~A})$. The measuring approach involved taking instantaneous noise measurements at various locations throughout the yard. As far as possible, the device was held at arm's length and at a height which was considered close to an average workers' hearing zone (i.e. 1.6-1.7m). A windshield was used to avoid the effect of the wind. After 30 seconds of data acquisition, the obtained data were averaged automatically by the device. The values recorded were then mapped onto the ship recycling yard plan in order to visualise the locations where noise levels are close to or exceeding $\mathrm{L}_{\mathrm{Aeq}} 80 \mathrm{~dB}$ : The level at which a worker will reach or exceed the lower exposure action value, as defined by the EU's Physical Agents (Noise) Directive (EC 2003b), if spending up to 8 hours in the location of the source of noise.

Following the scanning survey of the field, daily noise exposure of individuals will be conducted by using the most suitable measurement strategy for the ship recycling yard being investigated in this paper. A number of measurement strategies for occupational exposure assessment are listed in ISO 9612-2009 Acoustics Determination of Occupational Noise Exposure: Engineering method (ISO, 2009). These strategies are explained below.

Task based measurement: This strategy recommends to conduct noise measurements for the tasks which expose a worker to noise, which in turn reduces the measurement time (ISO, 2009). Therefore, before these measurements work should be analysed in order to understand the tasks involved. Task based measurement is appropriate when the worker conduct the tasks, which are well-defined and the noise conditions are well defined (ISO, 2009).

Job based Measurement: In this strategy, a number of random samples of noise exposure is taken during the job. Job-based measurements are relevant when typical work patterns and tasks are difficult to define or not practical to perform a detailed work analysis. While Jobbased measurements may lead to less effort for work analysis, actual measurement time for the samples is longer (ISO, 2009).

Full day measurement: This strategy is recommended when work patterns are not well defined and noise levels, which workers are exposed to, are varying. Full day measurement strategy is useful as it takes into account all the noise contributions within the work environment however the measurement time required is longer than previous strategies (ISO, 2009). 
Ship recycling workers investigated in this study have a fairly well-defined singular task, which makes 'task based measurement' strategy a good candidate for this study. However, due to safety concerns the ship recycling yard requested from authors to keep interaction with the worker at a minimum level in order to avoid any potential distraction. By also considering the difficulty to conduct these kind of measurement studies in an operational ship recycling yard, "Full Day Measurement" strategy was selected which is referred as a simpler but longer measurement strategy by Arezes et al. (2012).

For the measurement of exposure, three different worker types were chosen as a target group to cover those roles considered most at risk based on the initial investigation. Three torch cutters, one polygrab operator and one foreman were selected to conduct exposure measurements. More detailed information about selected trades and their job descriptions are provided below.

Torch cutters: In the ship recycling yard torch cutters are the workers who operate oxy-fuel torches to cut the ship's steel into smaller pieces for easy handling and transport (Figure 6), Torch cutters are generally located in a fixed location and they conduct cutting almost continuously during their 8 hour-shift. They are either located on board to cut blocks from the ship or they are located in the secondary zone to cut the steel from the blocks into smaller pieces. The main noise source which they are exposed to is the cutting noise.

Polygrab operators: this worker trade is responsible for operating the Polygrab (Figure 7). A Polygrab is a piece of heavy machinery which is used for handling and loading the small pieces of scrap steel onto trucks for transport. Polygrab operators are mainly exposed to the mechanical noise from the polygrab and irregular impact noise from loading steel plates.

Foreman: The foreman is the supervisor of the workers. His duty is to oversee the workers in the yard and organize the workers and to continuously inspect ongoing operations. This means that the foreman moves towards and away from various noise sources regularly during his 8hour shift.

For the measurement of personal noise exposure, dosimeters were utilised. The dosimeters were fully compliant with the IEC (1993) 61252:1993 Personal Sound Exposure Meters standard, certified as being recently calibrated in accordance with ISO (2005) EN ISO/IEC 17025 , and checked by using the internal acoustical calibrator in the reader unit before and after measurements. The noise dosimeters had an acoustic measurement range of $70 \mathrm{~dB}(\mathrm{~A})$ to $130 \mathrm{~dB}(\mathrm{~A}) \mathrm{RMS}$ and $120 \mathrm{~dB}(\mathrm{C})$ to $140 \mathrm{~dB}(\mathrm{C})$ peak. Accuracy was estimated at $\pm 2 \mathrm{~dB}$ for both peak and RMS noise. The dosimeter was placed on the worker's shoulder at the position which gave the best representation of the noise level. Figure 2 shows a field cutter who is conducting steel cutting while a dose badge, located just below his left ear, monitors his noise exposure throughout the working day. The device was attached carefully to ensure that mechanical impacts or covering of clothing would not lead to erroneous results. A briefing was provided for the workers being monitored on the purpose of the dosimeter, and the workers were asked to carry out their normal day to day working activities.

In order to ensure that the results are statistically significant and representative for workers with a similar role, it was desirable to repeat these measurements to increase the sample size. 
However, due to the limitations regarding access to the ship recycling yard, this was not possible to achieve. In order to mitigate this condition, where possible, the activities of the worker were observed and filmed during measurement in order to evaluate any unexpected deviation from the daily routine. By doing so, it was aimed to validate that the measurements were representative of such trade.

When determining the sample size in terms of numbers of workers to be included in this noise exposure study, specific consideration was given to ensuring that the sample represented the main roles within ship recycling yards. Regarding the duration of each measurement the aim was that most of the working shift of a worker was captured including the breaks. However, for especially a Foreman and Polygrab operator due to their unavailability longer measurements were not possible. Therefore, it needs to be noted that for these two ranks the reliability of overall exposure is lower. However, especially for a Polygrab operator the measurements were conducted during an approximately 1 hour loading task, and the overall exposure $\left(L_{E X, 8 h}\right)$ is calculated based on that. This approach can be considered as a conservative approach when various breaks with lower noise exposure are taken into account.

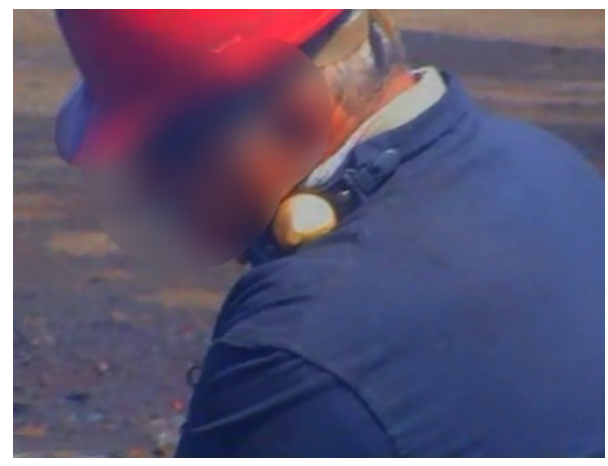

Figure 2: Field Cutter with a Dose Badge Located Just Below his Left Ear

\section{Theory}

After the measurements were taken, using the equivalent noise exposure data recorded by the noise dosimeters, A-weighted daily exposure levels using (Equation 1 (EC, 2003b) were calculated. In addition, the highest instantaneous noise level peak was identified and a graphical representation of the workers' noise exposure over time was produced.

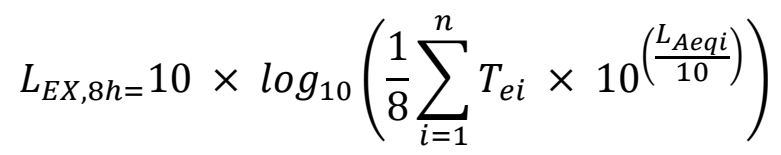

(Equation 1)

Where;

$L_{E X, 8 h}$ is 8 hours equivalent noise exposure level

LAeq is A weighted constant noise level,

$n$ is the number of partial noise levels of work operations

$T e$ is the duration of exposure to this noise level. 
From the results, a comparison with the exposure limit and action values (Table 1) that are defined in the EU's Physical Agents (Noise) Directive (EC 2003b) was then made.

Table 1: Exposure Limit and Action Values

\begin{tabular}{ccc}
\hline & Daily Exposure Levels & Peak Levels \\
\hline Exposure limit values & $\mathrm{L}_{\mathrm{EX}}, 8 \mathrm{~h}=87 \mathrm{~dB}(\mathrm{~A})$ & $\mathrm{P}_{\text {peak }}=200 \mathrm{~Pa}$ \\
or $140 \mathrm{~dB}(\mathrm{C})$
\end{tabular}

Finally, analysis was conducted to ascertain if the potential noise attenuation of selected hearing protection would be sufficient to reduce noise exposure levels below the action values. OSHA's method of hearing protection noise attenuation estimation OSHA (2014) was followed for this analysis whereby the Time Weighted Average (TWA) of the 'A' weighted RMS noise results in $\mathrm{dB}(\mathrm{A})$ are used in conjunction with the Noise Reduction Rate (NRR) of the chosen hearing protection, supplied by the manufacturer, and a $7 \mathrm{~dB}$ correction factor (Equation 2).

$$
\text { Estimated Exposure }(d B(A))=T W A(d B(A))-(N R R-7 d B)
$$

(Equation 2)

For dual protection, where a combination of two types of hearing protection are selected, the NRR of the higher rated protection (NRRh) was used, with the $7 \mathrm{~dB}$ correction factor, with an additional $5 \mathrm{~dB}$ added to represent the addition noise reduction rate (Equation 3 ).

$$
\text { Estimated Exposure }(d B(A))=T W A(d B(A))-((N R R h-7 d B)+5 d B)
$$

\section{(Equation 3)}

In addition, in order to take into consideration the differences in efficiency between the manufacturers' laboratory measured NRR and the reality of the workplace environment, the OSHA-recommended correction factor of $50 \%$ was applied to the measured results (Equation 4) and (Equation 5).

$$
\begin{aligned}
\text { Estimated Exposure }(d B(A))= & T W A(d B(A))-[(N R R-7 d B) x 0.5] \\
& (\text { Equation } 4) \\
\text { Estimated Exposure }(d B(A))= & T W A(d B(A))-[((N R R h-7) x 0.5)+5]
\end{aligned}
$$

(Equation 5)

\section{Results}

The yard under investigation, as seen in Figure 8, had a rectangular layout with an area of approximately 0.5 hectare. Due to confidentiality agreements, yard name, location and country information are not disclosed in this paper. The majority of the ship recycling activities were being conducted in the primary and secondary zones which were predominately located at the sea-shore interface end of the yard. At the opposite end of the yard, the administrative 
buildings, workshops and storage areas were located. Adjacent to the yard on both sides, two other ship recycling yards with similar layouts were present.

In this ship recycling yard, it was observed that blocks were cut using torch cutting equipment and removed from the obsolete vessel, and further processed into smaller pieces using torch cutting equipment in the secondary zone. Figure 3 shows a schematic representation of this process, which is repeated until the ship is completely dismantled.

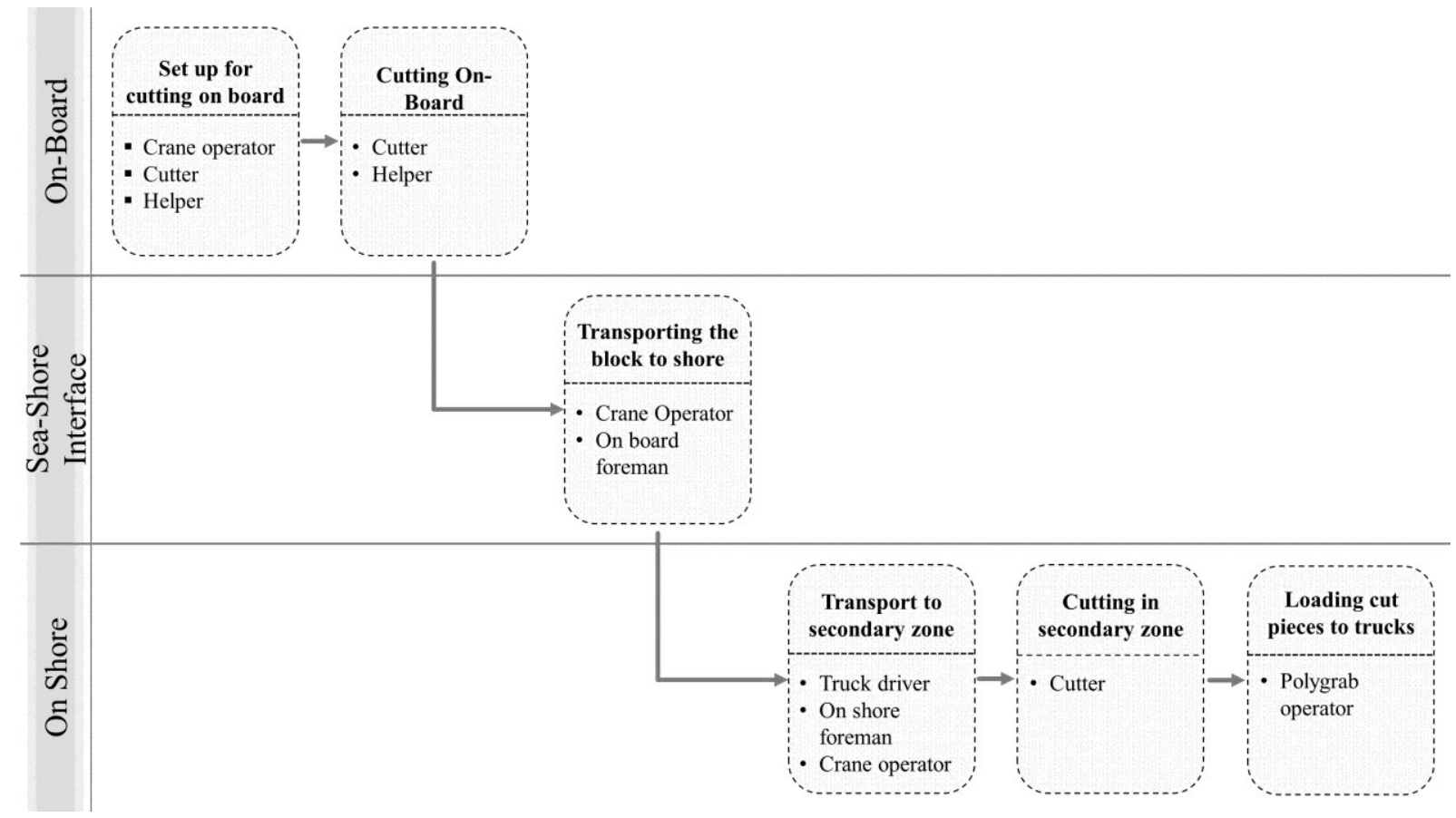

Figure 3: Flowchart of Dismantling Blocks from End-of-Life Ship

During the initial noise survey, normal ship recycling operations took place without any interruption/changes to work pattern due to survey. It was noted that potential sources of noise were: a mobile crane used for lifting blocks and transporting workers (Figure 4), a truck used to transport blocks to the secondary zone (Figure 5), torch cutting operations (Figure 6) and small poly-grab cranes used for gathering up small pieces of steel scrap (Figure 7). In addition, the various workers within the vicinity and their job tasks were also recorded.

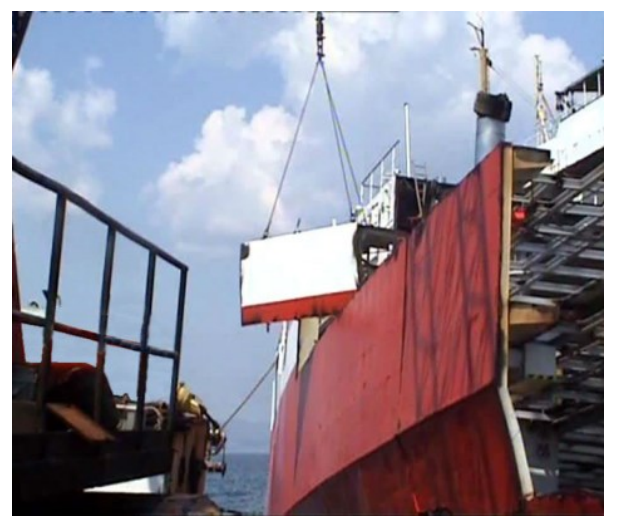

Figure 4: Mobile Crane in the Sea-Shore Interface 


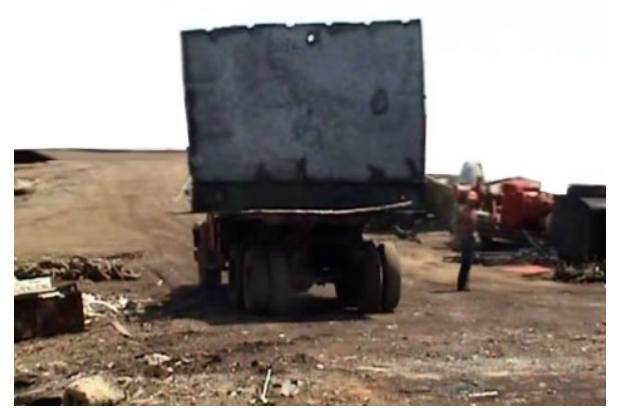

Figure 5: Transportation of Block to the Secondary Zone

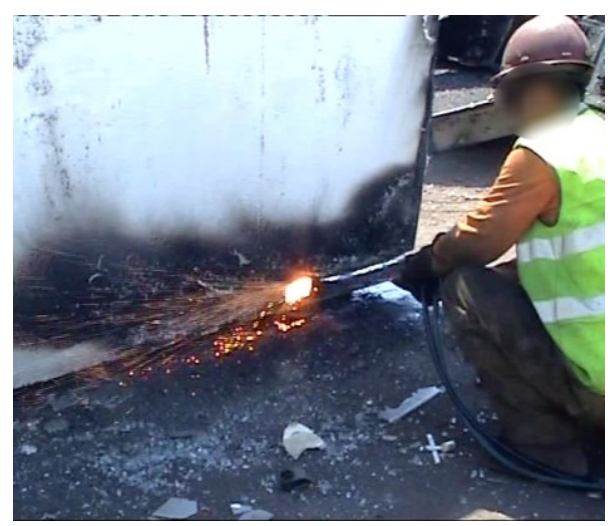

Figure 6: Torch Cutter in the Secondary Zone

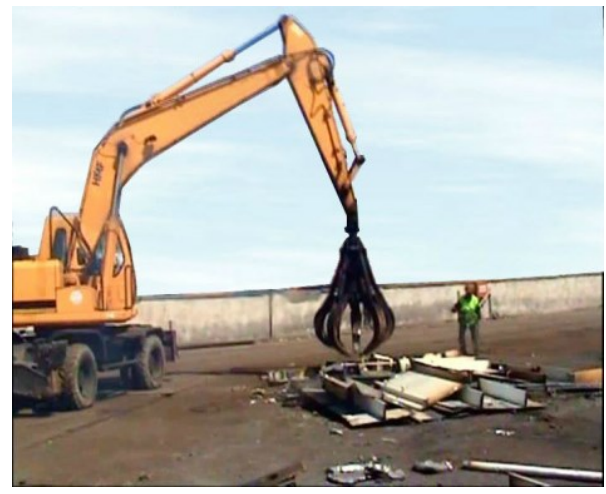

Figure 7: Poly-Grab Crane in the Secondary Zone

In total, 25 individual instantaneous noise measurements were recorded by a sound level meter at strategic intervals throughout the yard. The measured noise levels were within the accuracy of the measuring equipment. The specific locations of the measurements are presented in Figure 8, while the general noise measurement results for each zone are presented in Table 2. 


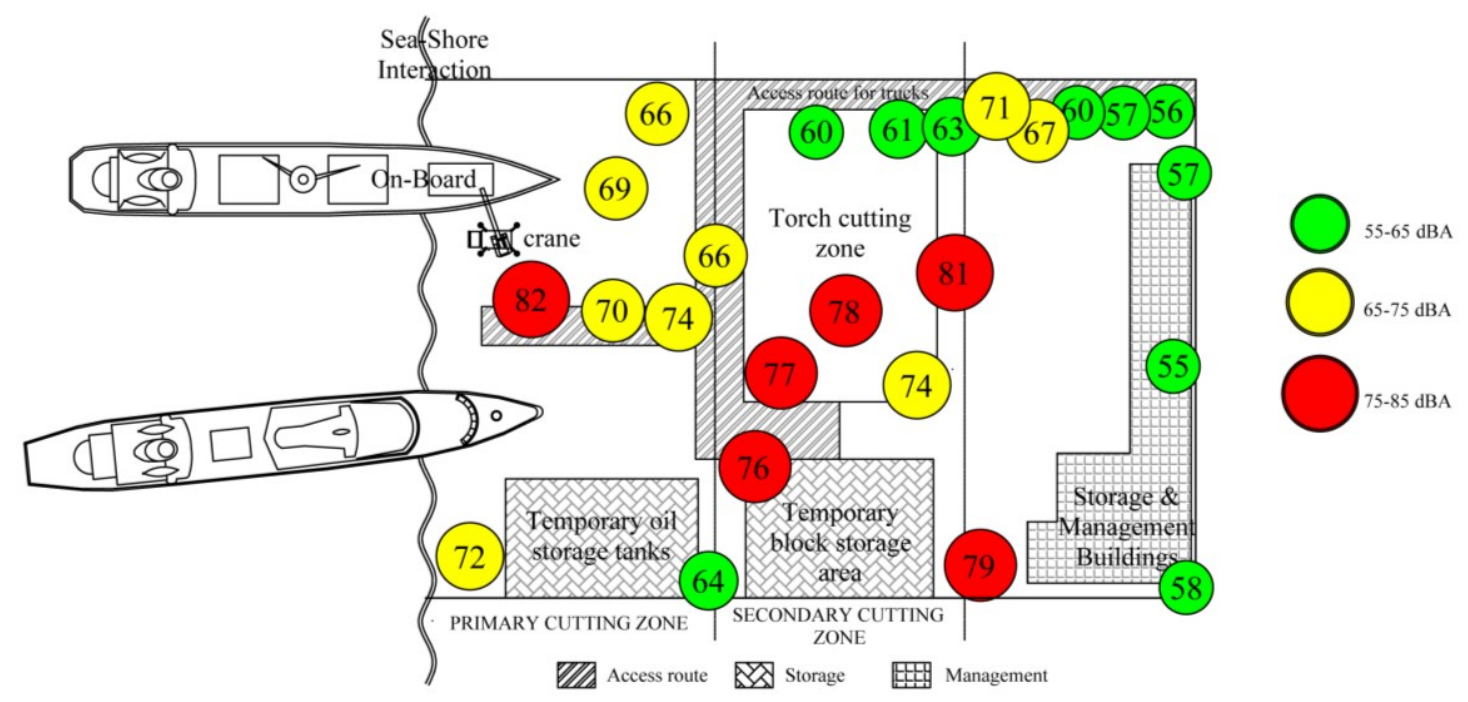

Figure 8: Noise Map of Ship Recycling Yard (numbers represent noise levels in $\mathrm{dB}(\mathrm{A})$ )

From Figure 8 and Table 2 it can be seen, as expected, that the noise levels tend to be higher in the primary and secondary zones of the yard, where the majority of ship recycling activities take place. Noise levels were observed to be at their highest in the secondary cutting zone, where torch cutting and general heavy plant traffic was present, and in the sea-shore interface, where on board torch cutting and a mobile crane was in operation next to the ship.

Out of the 25 measurements taken, only two of them exceeded $\mathrm{L}_{\text {Aeq }} 80 \mathrm{~dB}$ which can mean that employees assigned to tasks in these two locations for extended periods (equal or longer than 8 hours) may be at risk. One of the aforementioned measurements was taken in a location 15 metres away from an operating mobile crane $(82 \mathrm{~dB}(\mathrm{~A}))$. The other was in the secondary zone near operating trucks and torch cutting $(81 \mathrm{~dB}(\mathrm{~A}))$. Another important point to mention is the fact that these measurements were not made at the ear level of the worker concerned, instead the aim of these measurements was to identify the zones and activities with higher noise levels. Therefore, the results obtained from dose badges will better demonstrate the personal exposure.

Table 2: Highest and Lowest Noise Levels According to the Zone

\begin{tabular}{cccc}
\hline & Primary cutting Zone & Secondary Cutting Zone & $\begin{array}{c}\text { Storage \& } \\
\text { Management } \\
\text { Buildings }\end{array}$ \\
\hline $\begin{array}{c}\text { Number of } \\
\text { Measurements }\end{array}$ & 8 & 8 & 9 \\
\hline Lowest Noise Level & $64 \mathrm{~dB}$ & $60 \mathrm{~dB}$ & $55 \mathrm{~dB}$ \\
\hline Highest Noise Level & $82 \mathrm{~dB}$ & $81 \mathrm{~dB}$ & $79 \mathrm{~dB}$ \\
\hline $\begin{array}{c}\text { Average of } \\
\text { Measurements }\end{array}$ & $70.3 \mathrm{~dB}$ & $71.25 \mathrm{~dB}$ & 8.2 \\
\hline Standard Deviation & 5.7 & 8.4 & $\mathrm{~dB}$ \\
\hline
\end{tabular}


An unexpected high noise level measurement of $79 \mathrm{~dB}(\mathrm{~A})$ was observed near the storage and management buildings area. When measurement notes were investigated, it was found that during the sampling of this point a sand blasting operation was being conducted 15-20 metres away in the adjacent ship recycling yard. This highlighted the potential problem of additional noise emissions from neighbouring recycling yards contributing to workers' exposure to noise.

Overall, the results of the noise map show that 24 of the 26 measurements are below $80 \mathrm{~dB}(\mathrm{~A})$, which means that if a worker stays in these areas with the noise level below $80 \mathrm{~dB}(\mathrm{~A})$ for 8 hours without any hearing protection, their exposure value will not exceed the lower exposure action value defined by the EU Physical Agents Directive. However, the purpose of the initial noise survey was to identify zones for further investigation. It was therefore fully expected, due to the initial readings around identified zones being close to the $80 \mathrm{~dB}(\mathrm{~A})$ action value, that noise levels inside these zones, and certainly within the immediate vicinity of operations within them, exposure levels may exceed the action values and even the limit exposure level of $87 \mathrm{~dB}(\mathrm{~A})$. In addition, it was also expected that those workers who perform torch cutting on board the end-of-life vessel would also be exposed to high levels of noise.

After examining the preliminary results of the noise map, it was identified that the following workers within the identified zones were potentially at risk from noise exposure: torch cutters, polygrab operators and the foreman. It was therefore decided that conducting personal noise exposure surveillance on those workers who were deemed to be most at risk would be the best course of action.

Individual noise exposure surveillance of workers using dosimeters was carried out on 3 torch cutters, one poly-grab operator and one foreman. The results from the dosimeters attached to the various workers are presented in Figure 9, Figure 10, Figure 11, Figure 12, Figure 13 and Table 3.

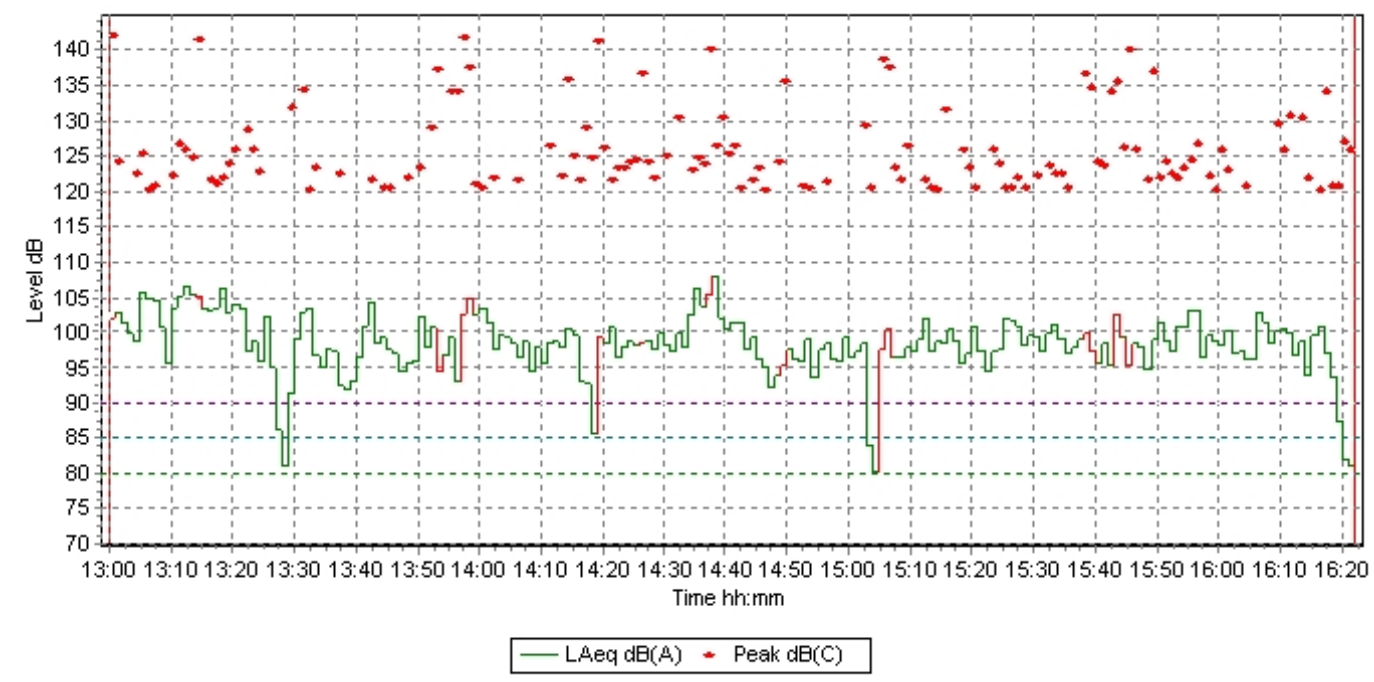

Figure 9: Noise Exposure of Torch Cutter 1 Over Time 
Table 3: Ship Recycling Workers' Personal Noise Exposure

\begin{tabular}{|c|c|c|c|c|c|}
\hline & $\begin{array}{c}\text { Torch } \\
\text { Cutter } 1 \\
\end{array}$ & $\begin{array}{c}\text { Torch } \\
\text { Cutter } 2 \\
\end{array}$ & $\begin{array}{c}\text { Torch } \\
\text { Cutter } 3 \\
\end{array}$ & $\begin{array}{l}\text { Poly-grab } \\
\text { Operator }\end{array}$ & Foreman \\
\hline $\begin{array}{l}\text { Measurement Duration: } \\
\text { hh:mm:ss }\end{array}$ & $03: 21: 52$ & $05: 25: 37$ & 05:33:00 & $00: 57: 20$ & $02: 14: 16$ \\
\hline Location & $\begin{array}{l}\text { Secondary } \\
\text { Zone }\end{array}$ & $\begin{array}{l}\text { On Board } \\
\text { Ship }\end{array}$ & $\begin{array}{l}\text { On Board } \\
\text { Ship }\end{array}$ & $\begin{array}{l}\text { Secondary } \\
\text { Zone }\end{array}$ & $\begin{array}{l}\text { Primary } \\
\text { Zone/Sea- } \\
\text { Shore } \\
\text { Interaction }\end{array}$ \\
\hline Working Hours Per Day & 8 & 8 & 8 & 8 & 8 \\
\hline $\begin{array}{l}\text { Noise Exposure Value: } \\
\text { LEx,8 hour dB(A) }\end{array}$ & 96.1 & 94.1 & 96.4 & 66.4 & 83.7 \\
\hline $\begin{array}{l}\text { Maximum Peak Value: } \\
\text { Lpeak } \operatorname{dB}(C)\end{array}$ & 141.6 & 143.7 & 144.0 & 133.1 & 130.4 \\
\hline $\begin{array}{l}\text { Exposure limit values (Daily): } \\
87 \mathrm{~dB}(\mathrm{~A})\end{array}$ & Exceeded & Exceeded & Exceeded & $\begin{array}{c}\text { Not } \\
\text { Exceeded } \\
\end{array}$ & $\begin{array}{c}\text { Not } \\
\text { Exceeded } \\
\end{array}$ \\
\hline $\begin{array}{l}\text { Upper exposure action values } \\
\text { (Daily): } \\
85 \mathrm{~dB}(\mathrm{~A})\end{array}$ & Exceeded & Exceeded & Exceeded & $\begin{array}{c}\text { Not } \\
\text { Exceeded }\end{array}$ & $\begin{array}{c}\text { Not } \\
\text { Exceeded }\end{array}$ \\
\hline $\begin{array}{l}\text { Lower exposure action values } \\
\text { (Daily): } \\
80 \mathrm{~dB}(\mathrm{~A})\end{array}$ & Exceeded & Exceeded & Exceeded & $\begin{array}{c}\text { Not } \\
\text { Exceeded }\end{array}$ & Exceeded \\
\hline $\begin{array}{l}\text { Exposure limit values (Peak): } \\
140 \mathrm{~dB}(\mathrm{~A})\end{array}$ & Exceeded & Exceeded & Exceeded & $\begin{array}{c}\text { Not } \\
\text { Exceeded }\end{array}$ & $\begin{array}{c}\text { Not } \\
\text { Exceeded }\end{array}$ \\
\hline $\begin{array}{l}\text { Upper exposure action values (Peak): } \\
137 \mathrm{~dB}(\mathrm{~A})\end{array}$ & Exceeded & Exceeded & Exceeded & $\begin{array}{c}\text { Not } \\
\text { Exceeded } \\
\end{array}$ & $\begin{array}{c}\text { Not } \\
\text { Exceeded } \\
\end{array}$ \\
\hline $\begin{array}{l}\text { Lower exposure action values (Peak): } \\
135 \mathrm{~dB}(\mathrm{~A})\end{array}$ & Exceeded & Exceeded & Exceeded & $\begin{array}{c}\text { Not } \\
\text { Exceeded }\end{array}$ & $\begin{array}{c}\text { Not } \\
\text { Exceeded }\end{array}$ \\
\hline
\end{tabular}

The torch cutter group cuts the steel plates into smaller pieces using oxy-fuel torches so that they can be transported to the storage zone or to steel mills with trucks. Surveillance on 'torch cutter 1' was started after lunch and continued for over 3 hours. In this time, the worker was continually cutting small pieces of steel from a larger block in the secondary zone. The worker stopped periodically to adjust his cutting equipment, change cutting position and took brief rest breaks (this is demonstrated in the drops in LAeq values specifically shown in Figure 9, between 13:25-13:30, 14:15-14:20 and 15:00-15:10). It was also observed that even in some cases where there was no torch cutting activity, the noise level $\left(L_{A e q}\right)$ at the ear of the worker still exceeded the level of $80 \mathrm{~dB}(\mathrm{~A})$. When the worker was torch cutting, the $L_{A e q}$ values ranged from $95 \mathrm{~dB}(\mathrm{~A})$

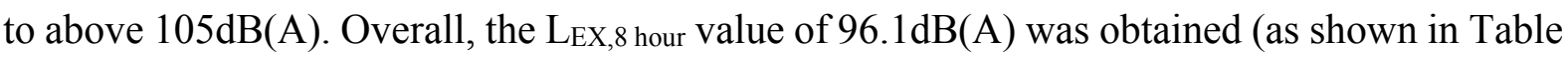
3) which exceeds the $87 \mathrm{~dB}(\mathrm{~A})$ limit value defined by the directive. It needs to be noted that when calculating Exposure Limit Value, the attenuation provided by any hearing protection should be taken into account. Values reported below are reflection of actual situation since currently there is no hearing protection used in ship recycling. However, the potential effect of such hearing protection devices is investigated and reported below in Table 4. For the peak values, 6 measurements were recorded between 135 to $137 \mathrm{~dB}$ and 10 above $137 \mathrm{~dB}$ while the maximum identified $\mathrm{L}_{\text {peak }}$ was $141.6 \mathrm{~dB}(\mathrm{C})$. In general, the incidents observed to be causing these peak value readings were: small combustion explosions while torch cutting, the striking of steel with an object to loosen cut parts and impact noises from the trucks loading and dropping steel plates on the ground. 


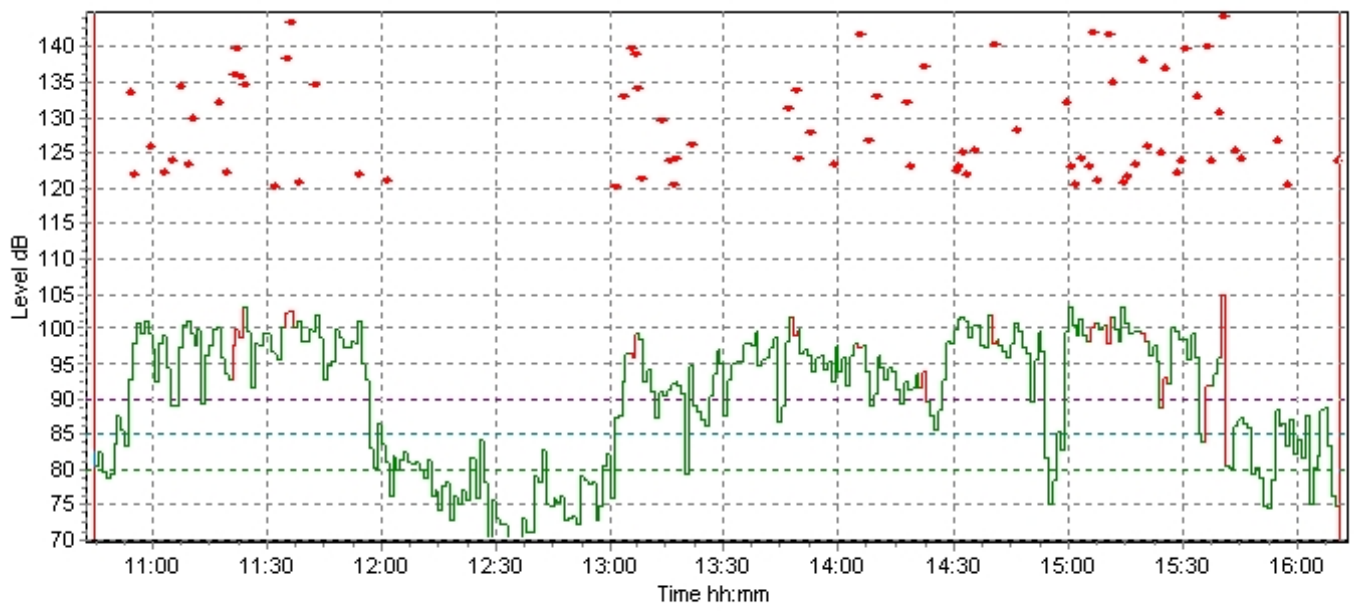

- LAeq $\mathrm{dB}(\mathrm{A}) *$ Peak $\mathrm{dB}(\mathrm{C})$

Figure 10: Noise Exposure of Torch Cutter 2 Over Time

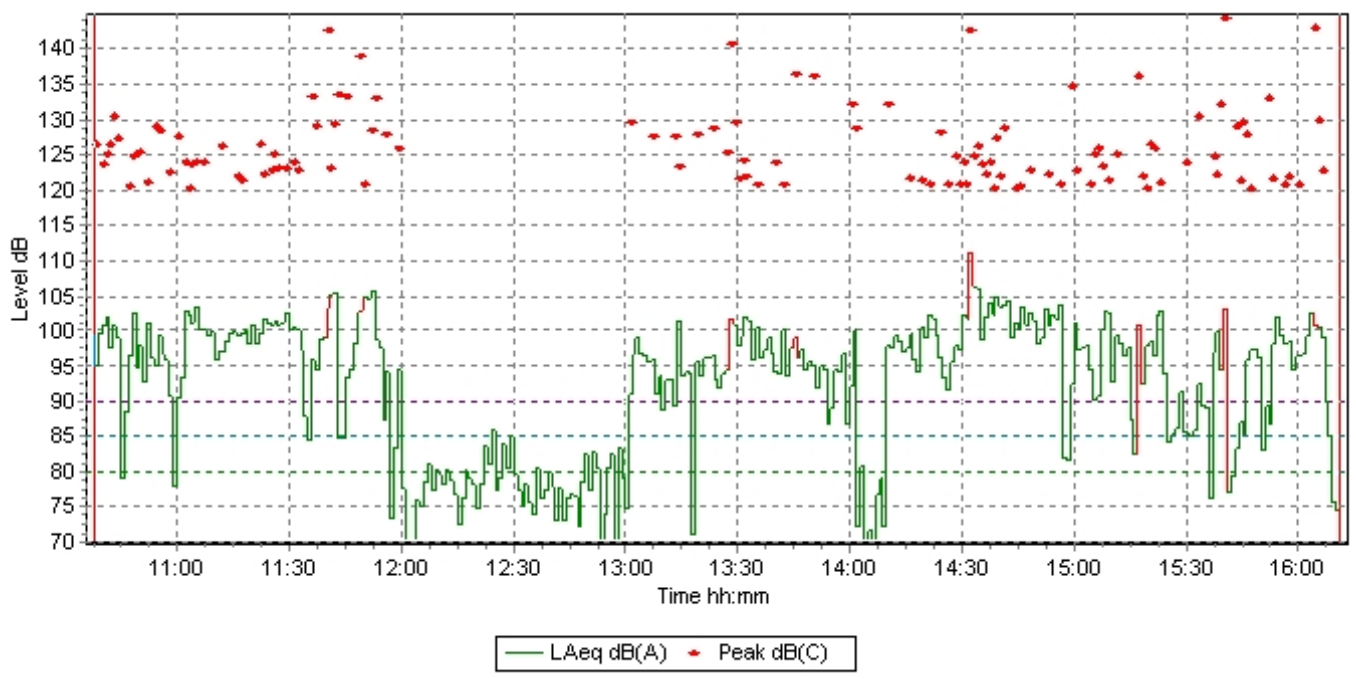

Figure 11: Noise Exposure of Torch Cutter 3 Over Time

For torch cutters 2 and 3, the surveillance commenced at approximately 10:30 am and continued for approximately 5.5 hours. Both workers were cutting on board a vessel which was being dismantled. Over the working period measured, the workers were observed to be torch cutting with various temporary intervals of reduced noise exposure attributed to the same reasons mentioned for torch cutter 1 . The various breaks taken by torch cutters working on board were generally observed to be more frequent than the secondary zone cutters as there was a greater need for them to adjust their set up and wait for cranes etc. Between 12:00 -13:00 both workers took a lunch break (Figure 10 and Figure 11). From Table 3, it can be seen that

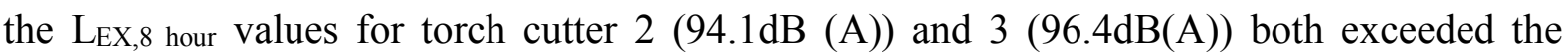

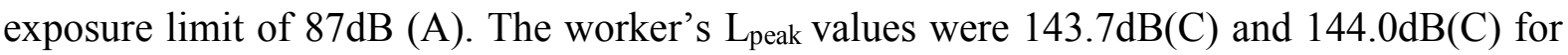
torch cutter 2 and 3 respectively. It was recorded that torch cutter 2 had 4 peak values recorded 
between 135 and $137 \mathrm{~dB}$ and 14 above $137 \mathrm{~dB}$. For torch cutter 3,4 values were between 135 and $137 \mathrm{~dB}$ and 6 were above $137 \mathrm{~dB}$. The identified instances of the peak values were attributed to small combustion explosions while torch cutting, the escape of gas from a tear in the fuel line of the cutting torch, the striking of steel with an object to loosen cut parts and impact noises of the crane lifting blocks for transportation to the secondary zone. An additional point to note for torch cutters 2 and 3 was that even during the lunch break they were being exposed to noise levels between $70-80 \mathrm{~dB}$ and this further highlights the hazardous nature of their working environment.

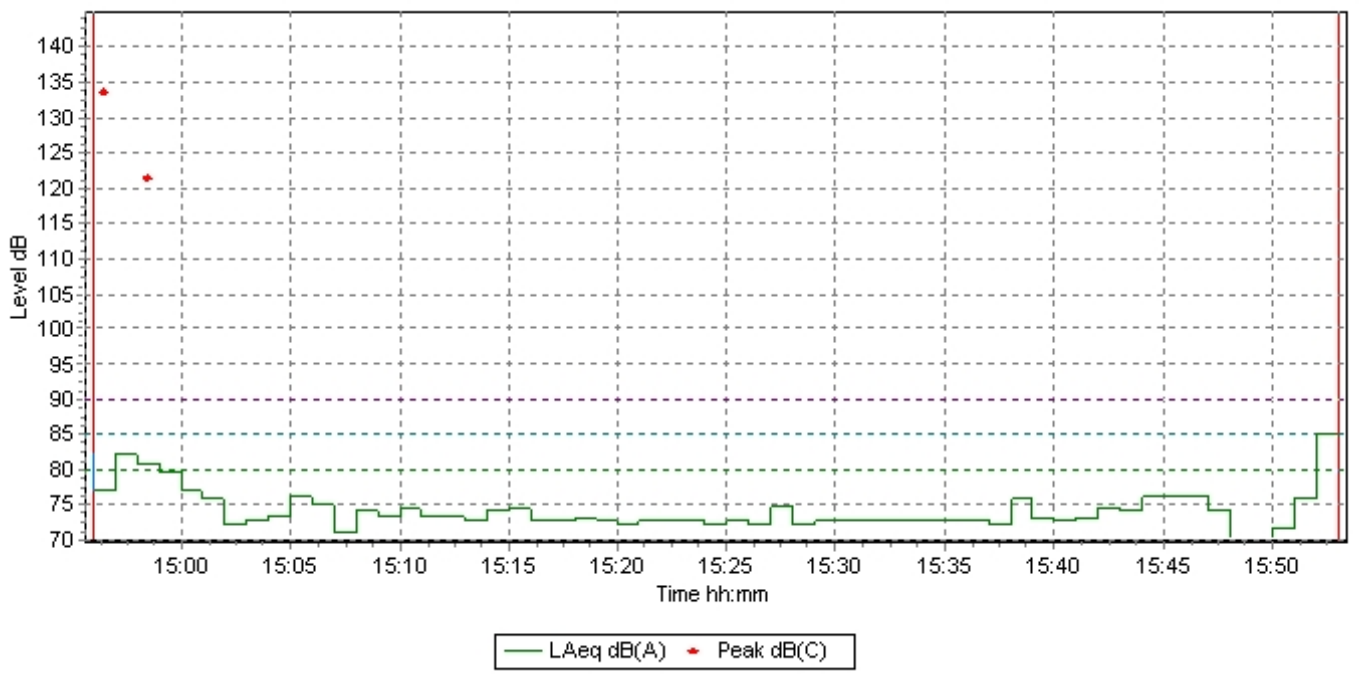

Figure 12: Noise Exposure of Poly-Grab Operator Over Time

The polygrab operator is tasked with moving the scrap metal, which has been cut from the blocks of the ship, from the secondary zone to a truck. The operator spends his time predominately in his cab which, as seen in Figure 12, keeps his exposure at around $75 \mathrm{~dB}(\mathrm{~A})$ or below. Also, the polygrab does not operate all day. As mentioned before, the polygrab is used to move the cut metal from the blocks. Cut metal is stacked in the secondary zone until it

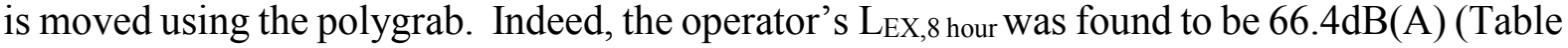
3 ) but this was in part due to the short measurement time (approximately 1 hour) afforded with the operator. At the beginning and end of his measured exposure, spikes above $80 \mathrm{~dB}(\mathrm{~A})$ can be seen; this reflects the time the operator spends in the yard environment before entering the $\mathrm{cab}$ and then subsequently exiting it. It can be clearly seen when outside his cab, exposure values above $80 \mathrm{~dB}(\mathrm{~A})$ can be expected. The poly-grab operator's $\mathrm{L}_{\text {peak }}$ was $133.1 \mathrm{~dB}(\mathrm{C})$. 


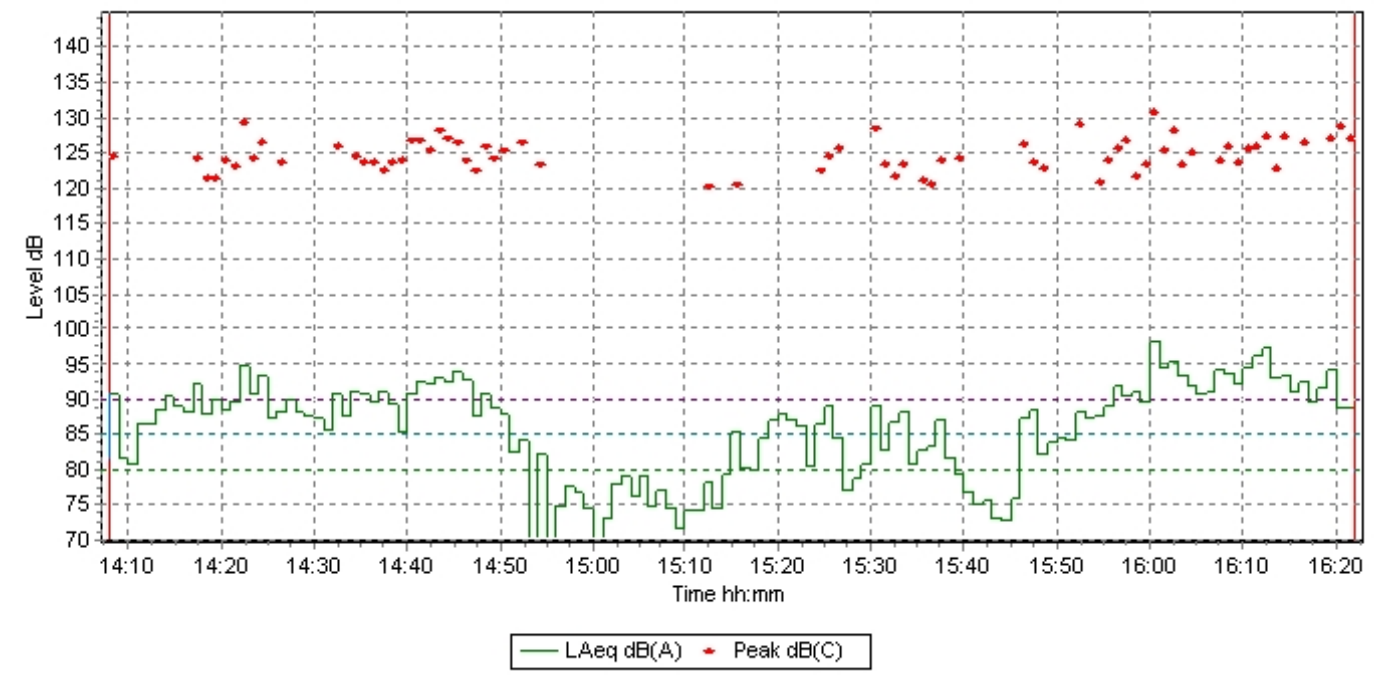

Figure 13: Noise Exposure of Foreman Over Time

The foreman is in charge of supervising operations predominately within the inter-tidal and secondary zones. During measurements, it was observed that the foreman was engaged as follows: supervising torch cutting in the secondary zone from 14:00-14:50, helping fix equipment from 14:50-15:20, supervising the secondary zone from 15:20-15:40, and visiting the administrative office from 15:40-15:50. In his final task, from 15:50-16:20, the foreman was supervising the crane lift of a block from the ship to a truck in the inter-tidal zone (Figure 13). Generally, the foreman kept a substantial distance from the actual torch cutting operations but was required to stand in close proximity to the crane during lift operations. Within the measurements taken, it was only possible to measure for around 2 hours and 15 minutes. However, the foreman is expected to be present for the whole working day. From Table 3 it

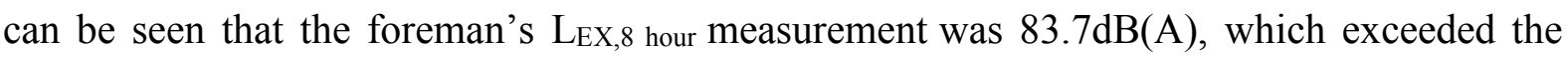
lower exposure action value of $80 \mathrm{~dB}(\mathrm{~A})$, and his $\mathrm{L}_{\text {peak }}$ was $130.4 \mathrm{~dB}(\mathrm{C})$.

\section{Discussion}

\section{Hearing Protection}

As required by EU Physical agents directive, when the exposure exceeds the Upper Exposure Action Value hearing protection should be provided and worn (EC, 2003b). Unfortunately, within the ship recycling yard under surveillance and indeed in all ship recycling operations observed by the authors, hearing protection is commonly not present or at best only the most basic types are utilised. In general, it is found that hearing protection is not being made available to ship recycling workers and/or is not worn on a large scale. From a study of 256 ship recycling workers by Unal (2011), less than $10 \%$ of workers surveyed mentioned that they wore hearing protection, with the most common hearing protection used being disposable earplugs. Similar observations can be verified in ship recycling yards in various countries, including developed countries. This highlights a very serious lack of awareness amongst ship recyclers about the dangerous levels of noise which they are exposed to. 
Table 4: Estimated Exposure after Hearing Protection Attenuation

\begin{tabular}{|c|c|c|c|c|}
\hline & No Protection & Earplugs & Earmuffs & Dual Protection \\
\hline NRR & & 30 & 31 & $\begin{array}{l}31 \text { Earmuffs } \\
30 \text { Earplugs }\end{array}$ \\
\hline \multirow[t]{2}{*}{$\begin{array}{c}\text { Estimated } \\
\text { Attenuation }\end{array}$} & & 11.5 & 12 & 17 \\
\hline & LEX,8 hour & & imated Exp & \\
\hline $\begin{array}{c}\text { Torch } \\
\text { Cutter } 1\end{array}$ & $\underline{96.1}$ & $\underline{84.6}$ & $\underline{84.1}$ & 79.1 \\
\hline $\begin{array}{c}\text { Torch } \\
\text { Cutter } 2\end{array}$ & $\underline{94.1}$ & $\underline{82.6}$ & $\underline{82.1}$ & 77.1 \\
\hline $\begin{array}{c}\text { Torch } \\
\text { Cutter } 3\end{array}$ & $\underline{96.4}$ & $\underline{84.9}$ & $\underline{84.4}$ & 79.4 \\
\hline Foreman & $\underline{83.7}$ & 72.2 & 71.7 & 66.7 \\
\hline
\end{tabular}

In order to protect against the noise exposure values measured within this study, appropriate hearing protection has to be carefully selected. In Table 4, the calculation of estimated exposures with various types of hearing protection is shown. The most common and high NRR grade of earmuffs and earplugs has been chosen (3M, 2015) and the estimated attenuation effect has been calculated in accordance with (Equation 5). From the results, it can be seen that the only protection option which can reduce noise exposure below the lower action limit of $80 \mathrm{~dB}(\mathrm{~A})$ for torch cutters is the combination of earplugs and earmuffs. For the foreman, it can be seen that either the earplugs or earmuffs on their own are sufficient. Therefore, even for the small minority of torch cutters who currently use earplugs, it can be seen that this is not sufficient protection to reduce their noise exposure below the lower exposure action value. The hearing protection specifically recommended within this study, for those at the highest risk of ONIHL, is earplugs used in conjunction with earmuffs which will provide sufficient attenuation.

\section{Situational Awareness and Safety Concerns}

During this study, it was identified that one of the main reasons workers do not wear hearing protection is the need to be able to communicate, hear warnings and heavy plant traffic, and generally have an enhanced awareness of their surroundings at all times. Due to the chaotic and unplanned nature of ship recycling activities, communication is important in avoiding hazards and warning those around of potential harm. Within ship recycling yards, exclusion zones for locations where people are torch cutting are not in force. Therefore, other workers and even heavy plant machinery tend to encroach into these spaces, resulting in the need for the workers to have an enhanced awareness of their surroundings. In order to address these issues, a wide range of improvements need to be made. Firstly, more education is required to increase the awareness amongst workers of the consequences of ONIHL and the risk factors causing it, to promote the usage of hearing protection. Secondly, engineering controls need to be enforced and implemented to create no entry zones, dedicated lanes for heavy plant traffic and dedicated drop zones for blocks to reduce the risk and fear of the workers being hit by a passing truck/falling block etc. Additionally, standard procedures and safety checks for lifting and transportation operations should be developed and implemented in order to increase assurances of safety during working while wearing hearing protection. By applying 
aforementioned simple engineering solutions, negative effects of wearing passive hearing protection on situational awareness can also be eliminated. Hence workers can further benefit from hearing protection.

Finally, it is suggested that hearing protection, which incorporates noise suppression with speech enhancement, is utilised. Using 'intelligent' hearing protection, which allows workers to communicate and remain situationally aware while working, could reduce the temptation or necessity of having to remove hearing protection and potential to expose workers to excess noise. Overall, care should be taken when choosing hearing protection for ship recycling operations. If workers are forced to remove hearing protection in order to communicate, this significantly reduces the effectiveness of the hearing protection. Likewise, if the worker cannot hear a warning shout, an avoidable accident or fatality could occur.

\section{Monitoring \& Health Surveillance}

In general, within maritime sector protecting workers against noise exposure is an area which is currently neglected and requires action (Kurt et al., 2016), unfortunately the situation in ship recycling yards is not any different. Further research and the implementation of a comprehensive hearing protection programme are urgently required to prevent further occurrence of ONIHL. A range of hearing protection, which is fit for purpose, comfortable and safe, should be provided to workers. The yard management should also strictly enforce the usage of the hearing protection at all times.

From observations, questioning and a comprehensive literature review, evidence of noise monitoring in the form of sound meter level readings and personal exposure dosimeters has been found to be non-existent within ship recycling. In addition, no evidence has been found, at a government level, of systematic and regular hearing checks being offered to all workers from ship recycling yards. From the results of this study, and related research, it can be concluded that ship recycling workers will be at risk of or may already be suffering from ONIHL. Therefore, it is the employers' legal responsibly to provide appropriate health surveillance to manage and prevent ONIHL. In addition, because of the high frequency nature of torch cutting noise, the prevalence of high frequency sensorineural hearing loss (SNHL) is also identified as a potential risk factor. Again, appropriate health surveillance should be provided.

\section{Practical applications}

The outputs of this research have shown that workers involved in cutting operations within ship recycling are exposed to high levels of noise. It is envisaged that the outcomes of this study are utilised by the appropriate authorities in ship recycling countries to ensure noise exposure regulations are enforced and adhered to. It is hoped that this research can contribute towards educating those who are in charge of occupational health and safety related issues within ship recycling yards about the potential sources of noise and the impacts of noise exposure. Finally, this research can provide the necessary foundation for suggesting and developing engineering and procedural measures to reduce noise emissions and prevent hazardous noise exposure. One such engineering solution that could be investigated is a design modification of the torch 
cutting nozzle that sacrifices the quality of the cutting finish, which is not required in ship recycling, for a lower noise emission profile.

\section{Conclusions}

This study has presented the results of noise exposure measurements taken in a real ship recycling environment. From the results of this study, all the torch cutters are shown to exceed the noise exposure limit values of $87 \mathrm{~dB}(\mathrm{~A})$ and $140 \mathrm{~dB}(\mathrm{C})$ as defined by the EU's Physical Agents (Noise) Directive (EC, 2003b). The foreman is shown to be above the lower exposure action value of $80 \mathrm{~dB}(\mathrm{~A})$. Therefore, the main finding of this research is that noise is a significant risk factor in ship recycling operations and that damage to and loss of workers' hearing is a serious possibility for those who are not wearing, or not correctly wearing, hearing protection. In particular, it has been shown that torch cutters experience the highest exposure but it is also strongly suspected that if fire watchers were monitored, their exposure would match closely those of their torch cutting colleagues due to their proximity to cutting operation.

It is believed that the results, discussion and recommendations of this study can be the foundation for further investigations within this area and can provide a substantial contribution towards improving the working conditions and occupational health of ship recycling workers.

\section{Limitations}

Within this study, a good representation of the noise exposure of ship recycling workers is presented in various zones around a typical ship recycling yard. Potential sources of error within this investigation included: mechanical impacts on the microphone, wind induced noise and noise reflection from the body of the worker. The potential unexpected peak values as a result of mechanical impacts were eliminated as far as possible through comparison with the activity logs of the workers. The wind induced noise was reduced through the use of windscreens and by operating the dosimeters within the allowable wind speed range provided by the manufacturer. The uncertainty of reflections from the body is included in the instrument's uncertainty level of $\pm 2 \mathrm{~dB}$.

A further uncertainty was noise emissions coming from surrounding yards. This issue was carefully monitored and authors identified only one measurement point where noise emissions from surrounding yard's activities influenced the noise measurement. However, in the scope of this study, authors did not conduct further investigation into this observation.

Another limitation relates to some of the peak noise measurements being close to or exceeding the upper range of the measurement device used. Therefore, accuracy of some of those reported peak noise levels may be unreliable. However, this issue was not considered to have a significant effect on the findings of this study.

\section{Further Research}

To the best knowledge of the authors, this study is the only investigation of workers' exposure to noise in a ship recycling context. Further research is required in the areas identified above, to improve knowledge on the effect noise has had on ship recycling workers in the past, and to better understand what effects it will continue to have at the present and in the future. In addition, development is also required in creating low cost practical engineering controls, 
effective and useable hearing protection and appropriate hearing protection programmes. Finally, more research is required into the impact of the various risk factors, individually and cumulatively, have had on ONIHL and the workers' health in general.

\section{Acknowledgements}

This research was conducted under the EU FP7 DIVEST Project (Grant Agreement Number SCP-GA-2008-218695-DIVEST). Therefore, the authors of this paper are glad to acknowledge the funding received from the European Commission for the DIVEST Project "Dismantling of Vessels in Enhanced Safety and Technology". 


\section{References}

3M, 2015. Hearing Solutions Catalog, in: Division, P.S. (Ed.). 3M, USA.

Alexopoulos, E.C., Tsouvaltzidou, T., 2015. Hearing loss in shipyard employees. Indian Journal of Occupational and Environmental Medicine 19 (1), 14.

Arezes, P.M., Bernardo, C., Mateus, O.A., 2012. Measurement strategies for occupational noise exposure assessment: A comparison study in different industrial environments. International Journal of Industrial Ergonomics 42 (1), 172-177.

Azizi, M.H., 2010. Occupational noise-induced hearing loss. The international journal of occupational and environmental medicine 1 (3 July).

Bhumika, N., Prabhu, G., Ferreira, A., Kulkarni, M., 2013. Noise. Induced Hearing Loss Still a Problem in Shipbuilders: A Cross. Sectional Study in Goa, India. Annals of medical and health sciences research 3 (1), 1-6.

Bogardus Jr, S.T., Yueh, B., Shekelle, P.G., 2003. Screening and management of adult hearing loss in primary care: clinical applications. Jama 289 (15), 1986-1990.

Chute, D.O., 2012. Noise Control Methods for Shipbuilding Atrium Environmental Health and Safety Services, LLC.

Cohen, A., 1974. Industrial noise and medical absence, and accident record data on exposed workers. Noise as a Public Health Problem. Washington DC: US Environmental Protection Agency (Report EPA 550/9-73-0008), 441-453.

EASHW, 2000. The state of occupational safety and health in the European Union: pilot study. European Agency for Safety Health at Work.

EC, 2003b. Directive 2003/10/EC of 6 February 2003 on the minimum health and safety requirements regarding the exposure of workers to the risks arising from physical agents (noise). . Official Journal of the European Union, L 42(46), pp. pp.38-44.

EC, 2013. The EU Ship Recycling Regulation.

Ferrite, S., Santana, V., 2005. Joint effects of smoking, noise exposure and age on hearing loss. Occupational medicine 55 (1), 48-53.

IEC, 1993. IEC 61252:1993 Personal Sound Exposure Meters standard.

IEC, I.E.C., 2003a. IEC 60942: 2003,““. Electroacoustics-Sound Calibrators.

IEC, I.E.C., 2003b. IEC 61672-1: 2003 Part 1 - Electroacoustics - Sound level meters - Part 1: Specifications.

ILO, 2004. Safety and health in shipbreaking: Guidelines for Asian countries and Turkey.

IMO, 2009. The Hong Kong International Convention for the Safe and Environmentally Sound Recycling of Ships. International Maritime Organization.

ISO, 2005. ISO/IEC 17025 General requirements for the competence of testing and calibration laboratories., International Standard, pp. pp.1-36.

ISO, 2009. ISO 9612:2009: Acoustics. Determination of occupational noise exposure. Engineering method, p. 43.

Kihlman, T., Lidén, G., Aniansson, G., 1976. Noise and hearing studies in shipyards. Environmental research 11 (2), 182-188.

Koh, D., Jeyaratnam, J., 1998. Occupational health in Singapore. International archives of occupational and environmental health 71 (5), 295-301.

Kurt, R.E., Khalid, H., Turan, O., Houben, M., Bos, J., Helvacioglu, I.H., 2016. Towards human-oriented norms: Considering the effects of noise exposure on board ships. Ocean Engineering 120, 101-107.

Melamed, S., Fried, Y., Froom, P., 2004. The joint effect of noise exposure and job complexity on distress and injury risk among men and women: the cardiovascular occupational risk factors determination in Israel study. Journal of occupational and environmental medicine 46 (10), 1023-1032. 
Mikelis, N., 2013. Ship recycling markets, BIMCO Bulletins. BIMCO.

Nelson, D.I., Nelson, R.Y., Concha-Barrientos, M., Fingerhut, M., 2005. The global burden of occupational noise-induced hearing loss. American journal of industrial medicine 48 (6), 446458.

Nilsson, R., Lidén, G., Sandén, Å., 1977. Noise exposure and hearing impairment in the shipbuilding industry. Scandinavian audiology 6 (2), 59-68.

OSHA, 2010. Safe Work Practices for Shipbreaking. Occupational Safety and Health Administration, U.S. Department of Labor.

OSHA, 2014. Noise and Hearing Conservation-Appendix IV: C. Methods for Estimating HPD Attenuation.

Available

at:

https:/www.osha.gov/dts/osta/otm/noise/hcp/attenuation_estimation.html [Accessed May 8, 2015].

Picard, M., Girard, S.A., Simard, M., Larocque, R., Leroux, T., Turcotte, F., 2008. Association of work-related accidents with noise exposure in the workplace and noise-induced hearing loss based on the experience of some 240,000 person-years of observation. Accident Analysis \& Prevention 40 (5), 1644-1652.

Ross, D., 1978. Welders' Health - Non-Respiratory Aspects. Metal construction 10 (5).

Tak, S., Calvert, G.M., 2008. Hearing difficulty attributable to employment by industry and occupation: an analysis of the National Health Interview Survey-United States, 1997 to 2003. Journal of occupational and environmental medicine 50 (1), 46-56.

Toppila, E., Pyykko, I., Starck, J., 2005. The use of hearing protectors among forest, shipyard and paper mill workers in Finland--a longitudinal study. Noise and Health 7 (26), 3.

Unal, N.B., 2011. A Statistical Study of the Occupational Health and Safety Hazards within the Turkish SD Industry (In Turkish). Gazi Universitesi, Ankara.

Wu, W.-T., Lin, Y.-J., Li, C.-Y., Tsai, P.-J., Yang, C.-Y., Liou, S.-H., Wu, T.-N., 2015. Cancer attributable to asbestos exposure in shipbreaking workers: a matched-cohort study. PloS one 10 (7).

Yueh, B., Shapiro, N., MacLean, C.H., Shekelle, P.G., 2003. Screening and management of adult hearing loss in primary care: scientific review. Jama 289 (15), 1976-1985. 